\title{
Yield Potential and Stability Indices as Methods to Evaluate Spring Wheat Genotypes under Drought
}

\author{
R. Ahmad', J. C. Stark ${ }^{2}$, A. Tanveer ${ }^{3}$ and T. Mustafa ${ }^{4}$
}

${ }^{1,3}$ Assistant Professors, Departments of Crop Physiology and Agronomy, University of Agriculture, Faisalabad, Pakistan, ${ }^{2}$ Professor, Department. of Plant, Soil and Entomological Sciences, University of Idaho, Research and Extension Center, Aberdeen, ID 83210., USA, ${ }^{4}$ Lecturer, Department of Computer Science, University of Agriculture, Faisalabad, Pakistan.

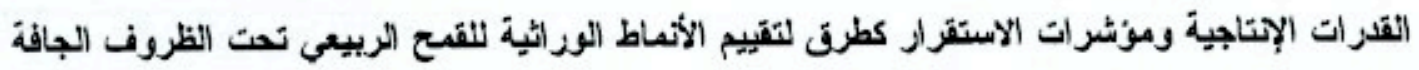

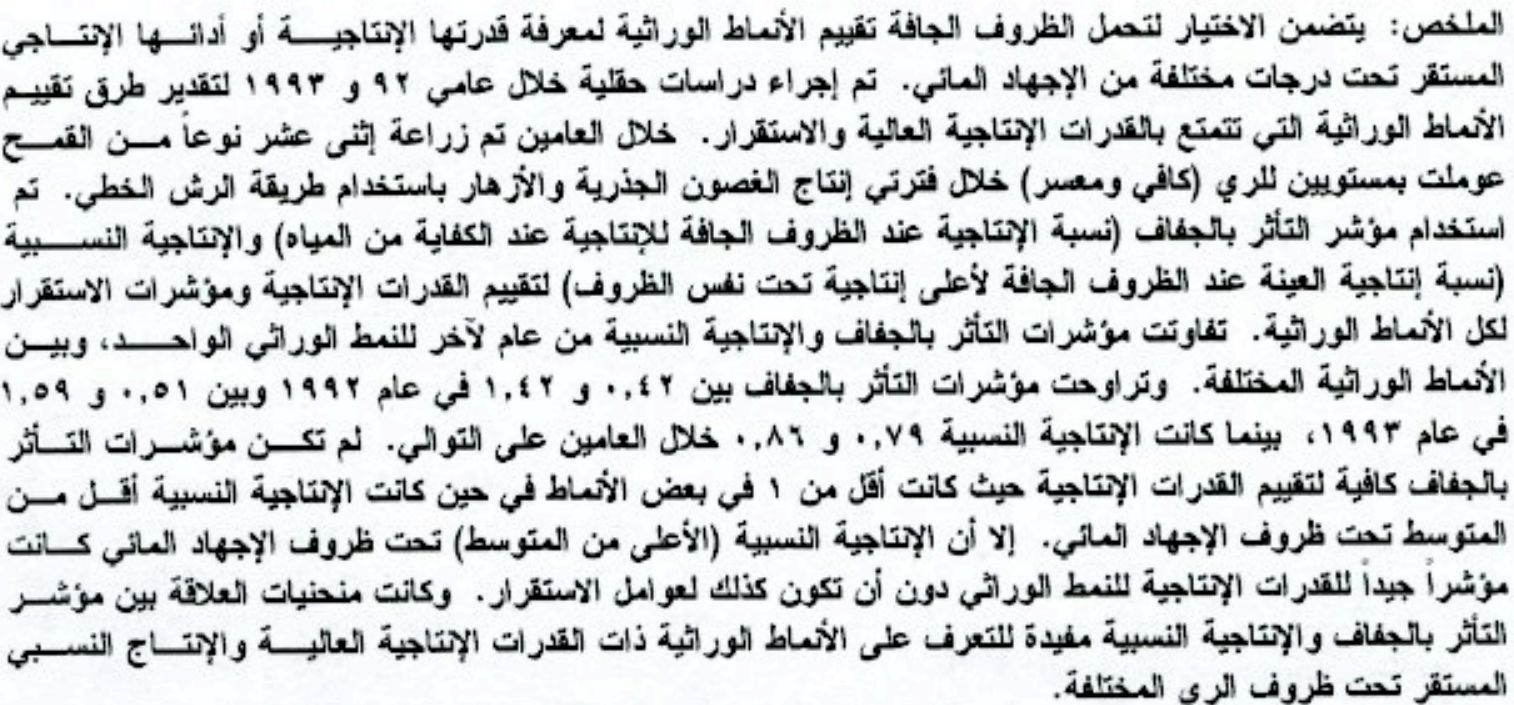

ABSTRACT: Selection for drought tolerance typically involves evaluating genotypes for either high yield potential or stable performance under varying degrees of water stress. Field studies were conducted in 1992 and 1993 to assess methods for evaluating genotypes with combined high yield potential and stability. In both years, 12 spring wheat (Triticum aestivum. L.) genotypes were grown under two irrigation levels (well-watered and stressed) imposed between tillering and anthesis with a line-source sprinkler irrigation system. Drought susceptibility index (the ratio of the yield of genotype in drought to the yield of the same genotype in well watered conditions standardized by the mean yield of all genotypes in drought and well watered conditions) and relative yield (yield of an individual genotype under drought divided by the yield of the highest yielding individual genotype in a population under drought) values were used to describe yield stability and yield potential of the 12 spring wheat genotypes. There were year-to-year variations in drought susceptibility index (DSI) and relative yield (RY) values within genotypes and changes in genotypic rankings within years. The DSI values ranged from 0.42 to 1.24 in 1992 and from 0.51 to 1.59 in 1993 . The mean RY were 0.79 and 0.86 in 1992 and 1993, respectively. The DSI did not provide a good indication of yield potential as some genotypes has DSI < 1 but RY lower than average under water-stressed conditions. The RY (higher than average) under water stress was a good indicator of yield potential of a genotype per se but gave no indication of yield stability. The plots of DSI vs. RY values were found useful in identifying genotypes with high yield potential and relatively stable yield performance under different moisture regimes.

$\mathrm{B}$

ecause of the lack of information on the genetic control of specific drought tolerance mechanisms, plant breeders selecting for drought resistance still largely depend on grain yield and yield stability under dry conditions (Fischer and Maurer, 1978). This is necessarily a slow and difficult process. Several 
selection criteria have been proposed to assist in this task. It is worthwhile, therefore, to look at the criteria that have been used to quantify stress tolerance on the basis of high and stable yield performance.

The most widely used criteria for selecting high yield performance are mean yield, mean productivity (average yield performance under stress and nonstress conditions) and relative yield performance in droughtstressed and more favorable environments. Lin and Binns (1988) used a superiority measure $(\mathrm{P})$ to compare productivity of genotypes across environments. The superiority measure is the difference between the observed yield of a genotype at a given location and the potential yield as indicated by the genotype with the highest yield at that location. Similarly, several methods for estimating yield stability are widely accepted and are in common use (Finlay and Wilkinson, 1963; Eberhart and Russell, 1966; Fischer and Maurer, 1978; Langer et al., 1979)

Yield stability analyses proposed by Finlay and Wilkinson (1963) and Eberhart and Russell (1966) are based on regression response and are often used where genotypes have been tested across a range of environments (i.e. multilocation testing). The approach used by Fisher and Maurer (1978) and Langer et al., (1979) involves the use of a drought susceptibility index (DSI), which characterizes the yield stability between two environments. The DSI is defined as the ratio of stressed to non-stressed yields for individual genotype in comparison to the ratio of stressed to nonstressed yields for all genotypes in the experiment. The DSI has been found to be highly correlated with yield stability as measured by Finlay-Wilkinson joint regression (regression of genotypic means at each site against the mean of all genotypes at each site) if moisture limitation is the primary factor determining environmental yield variation (Sinha et al., 1986). The DSI has been widely used in wheat for identifying genotypes with yield stability in moisture-limited environments (Fischer and Maurer, 1978; Clarke et al., 1984; Bruckner and Frohberg, 1987; Ceccarelli, 1987; Ehdaie et al., 1988; Bansal and Sinha, 1991; Clarke et al., 1992).

The ability of a cultivar to produce high and satisfactory yield over a wide range of stress and nonstress environment is very important. Finlay (1968) believed that stability over environments and yield potential are more or less independent of each other. Blum (1979) suggested that one method of breeding for increased performance under water stressed conditions might be to breed for superior yield under optimum conditions on the assumption that the best lines would also perform well under suboptimum conditions. Sojka et al. (1981), however, pointed out that a high yield baseline that allows a cultivar to do well over a range of environments does not imply drought resistance.
TABLE 1

Relative maturity and height of twelve spring wheat genotypes used for evaluation of drought resistance.

\begin{tabular}{lcc}
\hline \multicolumn{1}{c}{ Genotype } & Relative Maturity & Relative Height \\
\hline Amidon & Mid & T \\
Bannock & Mid & T \\
Chris & Late & T \\
Rick & Late & I-T \\
IDO 367 & Late & I-T \\
Pondera & Mid & I-T \\
IDO 369 & Late & I-T \\
Klasic & Early & S \\
Serra & Early & I \\
WPB 926 & Mid & I \\
Yecora Rojo & Early & S \\
Vandal & Late & I \\
\hline
\end{tabular}

Relative height: $\mathrm{T}=$ Tall, $\mathrm{I}=$ Intermediate and $\mathrm{S}=$ Short

They defined drought resistance as the ability to minimize yield loss in the absence of soil water availability. The ideal situation would be to have a highly stable genotype with high yield potential (Finlay and Wilkinson, 1963; Smith, 1982).

Relative yield (yield of an individual genotype under drought relative to that of the highest yielding genotype in the population) could be used to assess the yield potential of a genotype under water-stressed conditions. Higher relative yield shows that the genotype performed relatively well under drought. Pinter et al. (1990) found relative grain yield to be a useful criterion for assessing drought response of wheat genotypes. The combination of a high stability value (or low DSI value) and high relative yield under drought, therefore, may be a useful selection criterion for characterizing genotypic performance under varying degrees of water stress.

The objectives of this study, therefore, were to (i) evaluate the use of DSI and RY as measures of drought tolerance ability in spring wheat and (ii) identify some methods for selecting genotypes with high and stable performance over a range of water stress and nonstress environments.

\section{Materials and Methods}

Twelve hard red spring wheat genotypes were grown in 1992 and 1993 at the Aberdeen Research and Extension Center, Aberdeen, Idaho, under well-watered and water-stressed conditions. The 12 genotypes represent a relatively wide range of maturity and plant height (Table 1). Wheat was planted 13 May 1992 and 10 May 1993 on a Delco silt loam (coarse-loamy, mixed, mesic Xerollic Calciorthid). Both experiments 


\section{YIELD POTENTIAL AND STABILITY INDICES AS METHODS TO EVALUATE SPRING WHEAT GENOTYPES UNDER DROUGHT}

were seeded at $85-90 \mathrm{~kg} \mathrm{ha}^{-1}$ with an $18 \mathrm{~cm}$ row spacing. Each field received a pre-planting broadcast application of $110 \mathrm{Kg} \mathrm{N}$ ha ${ }^{-1}$ as ammonium nitrate. All other nutrients were determined to be present in adequate amounts.

A line-source sprinkler system (Hanks et al., 1976) was used to apply different amounts of water to two $143 \mathrm{~m}$ long vertical strips on each side of the sprinkler line. Horizontal strips of each genotype were 21 rows $(3.7 \mathrm{~m})$ wide and $31.7 \mathrm{~m}$ long and was oriented at right angles to the sprinkler line and the irrigation strip. Plots were arranged in a design similar to the split-block design with six replications (three on each side of the line source). Water stress was imposed at the beginning of tillering and continued until the completion of anthesis. All plots received the same amount of irrigation for the remainder of the growing season. Irrigation was scheduled to apply sufficient water to meet fully the water requirements of the wellwatered plots while maintaining available soil moisture in the root zone at least above $50 \%$. The daily crop water use was estimated using a modified Penman equation (Doorenbos and Pruitt, 1977). The frequency of irrigation was dependent upon the amount of rainfall, daily crop water use, and the rate of soil water extraction.

To measure the amount of water applied, catch cans were placed $60 \mathrm{~cm}$ above the ground in the middle of each irrigation strip at three different places in the field. Precipitation and other weather data were taken from the weather station of the Aberdeen Research Center. The amount of irrigation inclusive of precipitation applied to stressed plots was $197 \mathrm{~mm}$ and $286 \mathrm{~mm}$ of water in 1992 and 1993, respectively, while well-watered plots received 363 and $439 \mathrm{~mm}$, respectively.

Grain was harvested with a small-plot combine at maturity in mid-September of both years. An area 3.4 $\mathrm{m}^{2}$ in 1992 and $4.6 \mathrm{~m}^{2}$ in 1993 was harvested from the center of each plot for measurements of grain yield.

The measures of yield stability (DSI) and yield potential (RY) were calculated for each year from genotype mean grain yield. The DSI was calculated using a generalized formula (Fischer and Maurer, $1978)$, in which DSI $=(1-\mathrm{Yd} / \mathrm{Yw}) / \mathrm{D}$, where $\mathrm{Yd}=$ mean yield under drought, $\mathrm{Yw}=$ mean yield under well-watered conditions, and $\mathrm{D}=$ environmental stress intensity $=1-$ (mean yield of all genotypes under drought/mean yield of all genotypes under well-watered conditions). The relative yield under drought was calculated as the yield of a specific genotype under drought divided by that of the highest yielding genotype in the population.

\section{Results}

The 1992 growing season was substantially drier than normal and specifically drier than the summer of 1993 (Table 2). Weather conditions were markedly different from May to August in the 1992 and 1993 growing seasons. Total precipitation for the period was $40 \mathrm{~mm}$ in 1992 and $179 \mathrm{~mm}$ in 1993. Mean maximum temperature was $27.5^{\circ} \mathrm{C}$ in 1992 and $23.3^{\circ} \mathrm{C}$ in 1993 . These data indicate a greater potential for water and heat stress in 1992 than in 1993.

The 1993 grain yields under well-watered and water-stressed yields were higher than the corresponding 1992 yields (Tables 3 and 4). The ranges in yield under water-stressed and well-watered conditions in 1992 were $1289 \mathrm{~kg} \mathrm{ha}^{-1}$ and $3439 \mathrm{~kg} \mathrm{ha}^{-1}$, respectively. The genotypes IDO 367, IDO 369, and Rick produced the highest yields under water-stressed conditions and Chris, WPB 926, Vandal, and Bannock produced the lowest yields. Klasic, Yecora Rojo, IDO 367 , and IDO 369 were the highest yielding genotypes under well-watered conditions and Chris, Bannock, Amidon, and WPB 926 the lowest.

TABLE 2

May-August precipitation, mean maximum and minimum temperatures at Aberdeen, Idaho, U.S.A.

\begin{tabular}{|c|c|c|c|c|c|c|}
\hline \multirow[b]{2}{*}{ Month } & \multicolumn{3}{|c|}{1992} & \multicolumn{3}{|c|}{1993} \\
\hline & $\mathrm{P}^{1}(\mathrm{~mm})$ & $\mathrm{T} \max ^{2}\left({ }^{\circ} \mathrm{C}\right)$ & $\mathrm{T} \min ^{3}\left({ }^{\circ} \mathrm{C}\right)$ & $\mathrm{P}^{1}(\mathrm{~mm})$ & $\mathrm{T} \max .{ }^{2}\left({ }^{\circ} \mathrm{C}\right)$ & $\mathrm{T} \min .{ }^{3}\left({ }^{\circ} \mathrm{C}\right)$ \\
\hline May & 0.3 & 23.9 & 4.4 & 36.6 & 21.6 & 5.0 \\
\hline June & 25.1 & 26.1 & 7.7 & 67.8 & 21.6 & 6.1 \\
\hline July & 15.0 & 27.2 & 7.2 & 35.8 & 23.3 & 6.7 \\
\hline August & 0.0 & 32.2 & 6.1 & 38.9 & 26.7 & 7.2 \\
\hline Mean & 10.1 & 27.5 & 6.4 & 44.8 & 23.3 & 6.3 \\
\hline
\end{tabular}

${ }^{\mathrm{T}} \mathrm{P}=$ precipitation. ${ }^{2} \mathrm{~T} \max ,=$ mean maximum temperature. ${ }^{3} \mathrm{~T}$ min. $=$ mean minimum temperature. 


\section{TABLE 3}

Grain yields of 12 spring wheat genotypes under well-watered ( $\mathrm{Yw}_{\mathrm{w}}$ and water-stressed (Yd) conditions and corresponding relative yield (RY) and drought susceptibility index (DSI) values in 1992.

\begin{tabular}{ccccc}
\hline Genotype & $\mathrm{Yw}^{1}\left(\mathrm{~kg} \mathrm{ha}^{-1}\right)$ & $\mathrm{Yd}\left(\mathrm{kg} \mathrm{ha}^{-1}\right)$ & $\mathrm{RY}^{2}$ & $\mathrm{DSI}^{3}$ \\
\hline Klasic & 5725 & 2467 & $0.79(6)^{4}$ & $1.24(12)$ \\
Yecora Rojo & 5406 & 2594 & $0.83(4)$ & $1.13(10)$ \\
IDO 367 & 5204 & 3137 & $1.00(1)$ & $0.86(3)$ \\
IDO 369 & 5153 & 3123 & $0.96(2)$ & $0.90(4)$ \\
Serra & 5048 & 2372 & $0.76(9)$ & $1.15(11)$ \\
Pondera & 5022 & 2503 & $0.80(5)$ & $1.09(9)$ \\
Rick & 4689 & 2687 & $0.86(3)$ & $0.93(5)$ \\
Amidon & 4409 & 2408 & $0.77(7)$ & $0.99(6)$ \\
WPB 926 & 4254 & 2150 & $0.69(11)$ & $1.08(8)$ \\
Vandal & 4034 & 2189 & $0.70(10)$ & $0.99(7)$ \\
Bannock & 3875 & 2391 & $0.76(8)$ & $0.83(2)$ \\
Chris & 2286 & 1848 & $0.59(12)$ & $0.42(1)$ \\
Mean & 4592 & 2481 & 0.79 & 0.97
\end{tabular}

${ }^{1}$ Genotypes listed in descending order from highest to lowest yield under well-watered conditions.

${ }^{2} \mathrm{RY}=$ Yield of an individual genotype under drought divided by that of the highest yielding genotype in the population under drought. $\left.{ }^{3} \mathrm{DSI}=(1-\mathrm{Yd} / \mathrm{Yw}) / 1-\mathrm{Ydm} / \mathrm{Ywm}\right)$.

${ }^{4}$ Numbers in parentheses are genotypic ranks within each column.

The ranges in yield under water-stressed and wellwatered conditions in 1993 were $2870 \mathrm{~kg} \mathrm{ha}^{-1}$ and 4124 $\mathrm{kg} \mathrm{ha}^{-1}$, respectively (Table 4). Serra, IDO 367, IDO 369 , and Yecora Rojo were the highest yielding genotypes under well-watered conditions and Amidon, Bannock and Chris the lowest yielding. Under water-stressed conditions, WPB 926, IDO 367, Yecora Rojo, and Pondera produced the highest yields and Chris, Bannock, Klasic, and Serra the lowest.

Drought susceptibility index values ranged from 0.42 to 1.24 in 1992 and from 0.51 to 1.59 in 1993 (Tables 3 and 4). There was less variation in DSI in 1992 (more values were closer to 1) than in 1993. In 1992, Amidon, Bannock, Chris, Rick, IDO 367, IDO 367 , and Vandal were relatively drought resistant (DSI $<$ 1), while Klasic, Yecora Rojo, Serra, Pondera, and WPB 926 were relatively drought susceptible (DSI $>1$ ). In 1993, Amidon, Bannock, Chris, Pondera, WPB 926 and Yecora Rojo were relatively drought resistant (DSI $<1$ ), while Serra, IDO 367, IDO 369, Rick Yecora Rojo, and Vandal were relatively drought susceptible (DSI $>1$ ).

The mean relative grain yields under drought were 0.79 and 0.86 in 1992 and 1993, respectively. In 1992, IDO 367, IDO 369, Rick, and Yecora Rojo were relatively high yielding under drought $(\mathrm{RY}>$ mean $\mathrm{RY})$, while Chris, WPB 926, Vandal, and Serra were relatively low yielding ( RY < mean RY). In 1993, WPB 926, Pondera, IDO 367 , and Yecora Rojo produced relatively high yields under water-stressed conditions while Chris,
Bannock, Klasic, and Serra produced relatively low yields.

Ranking the 12 genotypes according to RY and DSI showed considerable differences between years for certain genotypes. The most notable of these was WPB 926 which had an RY ranking of 11 and 1, and a DSI ranking of 8 and 2 in 1992 and 1993 , respectively.

Plots of DSI vs. RY for the 12 genotypes were used to graphically represent genotype drought response (Figure 1). The numerical designations in these figures refer to the 12 genotypes as presented in Table 1 . The horizontal and vertical lines in the chart represent the DSI values of 1 and the average RY values, rerspectively.

The numbers in the fourth quadrate represent genotypes with relatively high yield stability (DSI $<1$ ) and higher than average RY. Genotypes in the 2nd quadrate represent genotypes with relatively low yield stability (DSI > 1) and lower than average RY under water-stressed conditions.

Although the numbers for two years are quite variable, the genotypes (4) Rick, (5) IDO 367, (7) IDO 369, (11) Yecora Rojo and (6) Pondera generally exhibited average to above average RY values and reasonably good yield stability. By comparison, the genotypes (1) Amidon, (2) Bannock, and (3) Chris were relatively stable but generally produced below average yields under drought. The other genotypes showed a more variable response to drought during the two years of study. 


\section{YIELD POTENTIAL AND STABILITY INDICES AS METHODS TO EVALUATE SPRING WHEAT GENOTYPES UNDER DROUGHT}

TABLE 4

Grain yields of 12 spring wheat genotypes under well-watered (Yw) and water stressed (Yd) conditions and corresponding relative yield (RY) and drought susceptibility index (DSI) values in 1993.

\begin{tabular}{|c|c|c|c|c|}
\hline Genotype & $\mathrm{Yw}^{\prime}\left(\mathrm{kg} \mathrm{ha}^{-1}\right)$ & $\mathrm{Yd}\left(\mathrm{kg} \mathrm{ha}^{-1}\right)$ & $\mathrm{RY}^{2}$ & $\mathrm{DSI}^{3}$ \\
\hline Serra & 8020 & 4998 & $0.84(10)^{4}$ & $1.59(11)$ \\
\hline IDO 367 & 7851 & 5915 & $0.99(3)$ & $1.04(5)$ \\
\hline IDO 369 & 7112 & 5099 & $0.86(2)$ & $1.19(7)$ \\
\hline Yecora Rojo & 7098 & 5648 & $0.95(8)$ & $0.86(10)$ \\
\hline Rick & 7073 & 5136 & $0.86(9)$ & $1.16(12)$ \\
\hline Vandal & 7051 & 5199 & 0.87 (4) & $1.11(3)$ \\
\hline Pondera & 6880 & 5643 & $0.95(6)$ & $0.76(9)$ \\
\hline Klasic & 6850 & 4849 & $0.81(7)$ & $1.23(4)$ \\
\hline WPB 926 & 6848 & 5959 & $1.00(1)$ & $0.54(2)$ \\
\hline Amidon & 6426 & 5132 & $0.86(5)$ & $0.85(8)$ \\
\hline Bannock & 5476 & 4813 & $0.81(11)$ & $0.51(1)$ \\
\hline Chris & 3896 & 3089 & $0.52(12)$ & $0.87(6)$ \\
\hline Mean & 6715 & 5123 & 0.86 & 0.98 \\
\hline $\mathrm{LSD}_{005}$ & 536 & 1061 & & \\
\hline
\end{tabular}

Genotypes listed in descending order from highest to lowest yield under well-watered conditions.

${ }^{2} \mathrm{RY}=\mathrm{Yield}$ of an individual genotype under drought divided by that of the highest yielding genotype in the population under drought. $\left.{ }^{3} \mathrm{DSI}=(1=\mathrm{Yd} / \mathrm{Yw}) / 1-\mathrm{Ydm} / \mathrm{Ywm}\right)$.

Numbers in parentheses are genotypic ranks within each column.

\section{Discussion}

The results of this study showed large year-to-year shifts in the DSI values of certain genotypes. The yearto-year variation in DSI may be attributed to substantially different environmental conditions during the two years of study. Timing of water stress in relation to the development of different genotypes (Clarke et al., 1984) or lack of adaptation to favorable environments (Baker, 1987) could be other possible causes of variation in DSI. The results of this study are in good agreement with the early findings of Clarke et al. (1984), Bruckner and Frohberg (1987) and Clarke et al. (1992), when they reported considerable variation in DSI values of certain genotypes of both across and within years.

Genotypes with low DSI values can be considered to be drought resistant (Bruckner and Frohberg, 1987), because they exhibited smaller yield reductions under water-stressed compared with well-watered conditions than the mean of all genotypes. However, the low DSI values may not necessarily give a good indication of drought resistance of a genotype. For example, genotypes that exhibit smaller than average yield changes between stressed and nonstressed environments were often low yielding genotypes. Such genotypes can be less adapted to nonstressed environments due to factors such as lodging, disease and shattering or low harvest index. Chris is a good example of this response. Chris had low DSI values in both years and exhibited a low yield potential and a high susceptibility to lodging. Using the DSI definition of drought resistance, based on minimization of yield reductions under dry compared with favorable conditions, Chris would be designated as drought resistant due to its low DSI values. However, Chris had the lowest yields under water-stressed conditions in both 1992 and 1993. Therefore, the low DSI values for Chris relate to a lack of yield production under well-watered conditions rather than to its ability to tolerate water stress.

The DSI has sometimes been represented as providing a measure of genotypic yield potential under drought (Bruckner and Frohberg, 1987). However, DSI does not account for differences in yield potential among genotypes (Clarke et al., 1992). DSI actually provides a measure of yield stability based on minimization of yield loss under stressed compared to nonstressed conditions rather than on yield level under dry conditions per se (Clarke et al., 1984). Therefore, a stress tolerant genotype, as defined by DSI, need not have a high yield potential as previously illustrated by the response of Chris.

Mean yield or RY may be another approach to evaluate the genotypic performance under drought conditions. Sojka et al. (1981), however, pointed out that a high yield base-line that allows a genotype to do well over a range of environments does not imply drought resistance. The ideal situation, therefore, would be to have highly stable genotypes with high yield potential 


\section{AHMAD, STARK, TANVEER AND MUSTAFA}
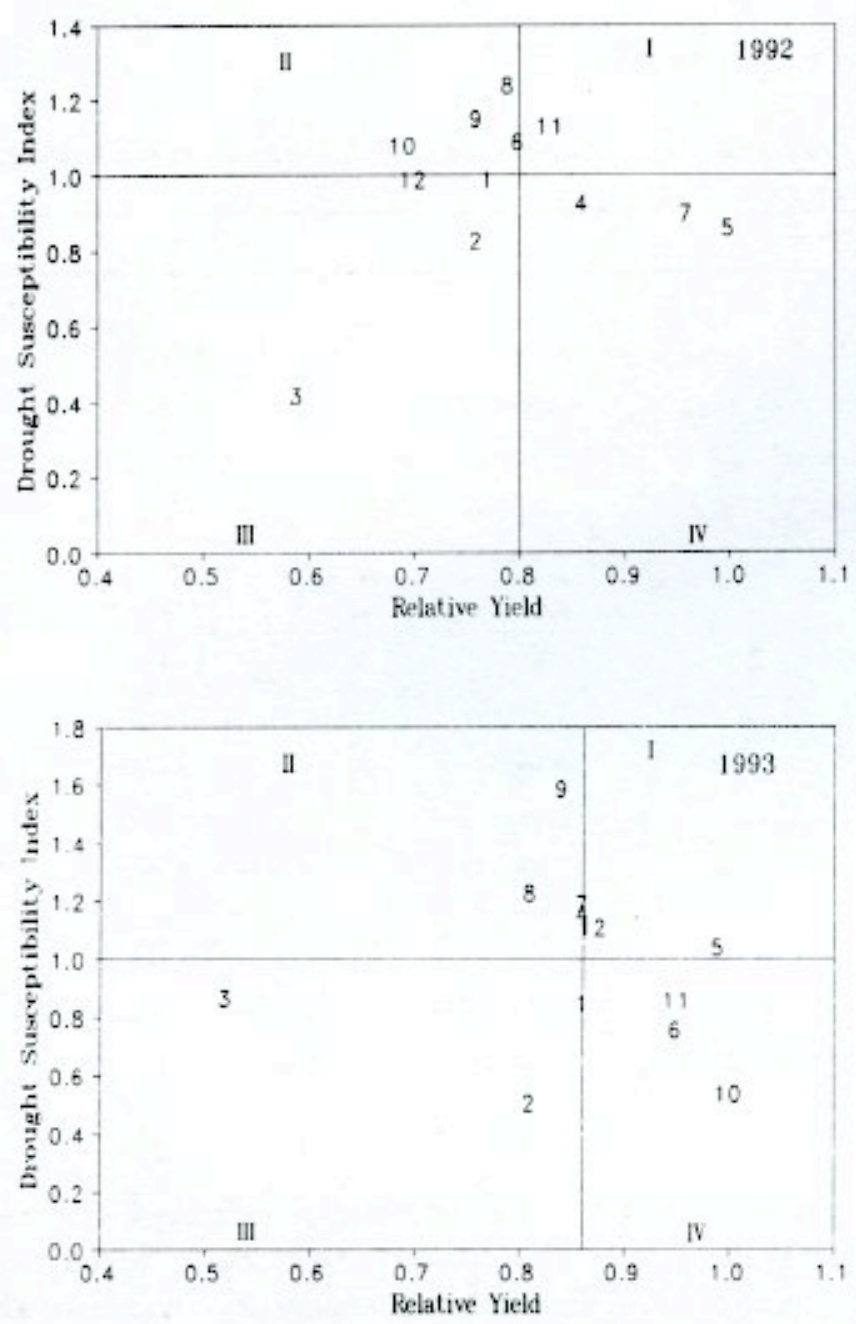

Figure 1. Relationship between drought susceptibility index and relative yield for 1992 (top) and 1993 (bottom). Numerical designations refer to the 12 genotypes as presented in Table 1. Horizontal and vertical lines in the charts represent drought susceptibility index values of 1 and average relative yields, respectively.

Finlay and Wilkinson, 1963; Smith, 1982). Genotypes with above average RY under drought and DSI values less than 1.0 would appear to have the desired combination of high yield and stable performance across a range of moisture environments.

The use of DSI for quantification of genotypic performance under drought appears to have limitations. It does not account for differences in yield potential. There is no common base for genotypic comparison under different environments using DSI (Clarke et al., 1992). The factors responsible for the lack of yield production under high-moisture conditions tend to distort the DSI values, creating an inaccurate indication of drought resistance. Moreover, because DSI calculations are based on the ratio of stressed to nonstressed yields, both highand low-yielding genotypes can have the same DSI values if both have the same proportional yield change from stressed to nonstressed conditions.
The use of DSI for drought tolerance screening studies may be of interest if research objectives are to look for particular drought tolerant traits that could be incorporated into genotypes with higher yield potential. On the other hand, yield or RY can only identify genotypes with high yield potential under specific environments. There seems to be no simple method of rating genotypes which could assist in selection of genotypes for high and stable yield performance over a range of environments. The plots of DSI vs. RY under drought is a potential method for evaluating genotypes for high and stable yield performance:

\section{References}

Baker, R.J. 1987. Differential response to environmental stress. p. 492-504. In: N.C. Weir et al.(ed.) Proc. Int. Conf. on Quantitative Genetics, 2nd Raleigh, Sinauer Association, Sunderland, MA. pp.492-504.

Bansal, K.C., and S.K. Sinha. 1991. Assessment of drought resistance in 20 accessions of Triticum aestivum and related species. I. Total dry matter and grain yield stability. Euphytica 56:7-14.

Blum, A. 1979. Genetic improvement of drought resistance in crop plants: A case for sorghum. p. 495-545. In H. Mussell, and R.C. Staples (Ed.) Stress Physiology In Crop Plants. Wiley Interscience, New York.

Bruckner, P.L. and R.C. Frohberg. 1987. Stress tolerance and adaptation in spring wheat. Crop Sci. 27:31-36.

Ceccarelli, S. 1987. Yicld potential and drought tolerance of segregating populations of barley in contrasting environments. Euphytica 36:265-273.

Clarke, J.M., R.M. DePauw, and T.F. Townley-Smith. 1992. Evaluation of methods for quantification of drought tolerance in wheat. Crop Sci. 32:723-727.

Clarke, J.M., T. F. Townley-Smith, T.N. McCaig, and D.G. Green. 1984. Growth analysis of spring wheat cultivars of varying drought resistance. Crop Sci. 24:537-541.

Doorenbos, J. and W.O. Pruitt. 1977. Guideline for predicting crop water requirements. FAO Irrig. Drain. Paper 24. FAO, Rome.

Eberhart, S.A. and W.A. Russell. 1966. Stability parameters for comparing varieties. Crop Sci. 6:36-40.

Ehdaie, B., J.G. Waines, and A.E. Hall. 1988. Differential responses of landrace and improved spring wheat genotypes to stress environments. Crop Sci. 28:838-842.

Finlay, K.W. 1968. The significance of adaptation in wheat breeding. p. 742-754. In: Proc. 3rd International Wheat Genetics Symposium, 5-9 August, Australian Academy of Sciences, Canberra, A.C.T.

Finlay, K.W. and G.N. Wilkinson. 1963. The analysis of adaptation in plant breeding programs. Aust. J. Agric. Res. 14:742-754.

Fischer, R.A. and R. Maurer. 1978. Drought resistance in spring wheat cultivars. I. Grain yicld response. Aust. J. Agric. Res, 29:897-907.

Hanks, R.J., J. Keller, V.P. Rasmussen, and G.D. Wilson. 1976. Line source sprinkler for continuous variable irrigation-crop production studies. Soil Sci. Soc. Amer. J. 40:426-429.

Langer, I., K.J. Frey, and T. Bailey. 1979. Association among productivity, production response and stability indices in oat varieties. Euphytica 28:17-24.

Lin, C.S. and M.R. Binns. 1988. A superiority measure of cultivar performance for cultivar $\times$ location data. Can. J. Plant Sci. 68:193-198. 
Pinter Jr, P.J., G. Zipoli, R.J. Reginato, R.D. Jackson, and S.B. Idso, 1990. Canopy temperature as an indicator of differential water use and yield performance among wheat cultivars. Agricultural Water management. 18:35-48.

Sinha, S.K., P.K. Aggrawal, G.S. Chaturverdi, and A.K. Singh. 1986. Performance of wheat cultivars in a variable water environment. I. Grain yield stability. Field Crops Res. 13:289-299.
Smith, E.L. 1982. Heat and drought tolerant wheats of the future. p. 141-147. In Proceedings of the National wheat Research Conference. USA-ARS, Beltville, Maryland. pp 141-147.

Sojka, R.E., L.H. Stolzy, and R.A. Fischer. 1981. Seasonal drought response of selected wheat cultivars. Agron J. 73:838-845. 